\section{Impact of stereopsis on quality of life}

\author{
Abstract \\ Purpose To investigate the impact of \\ stereopsis on vision-related quality of life and \\ general health status of the elderly. \\ Methods A quota of 200 subjects aged 65 \\ years or older and had their households \\ registered in Guando district was recruited for \\ a general physical examination including \\ ophthalmic evaluation. A structured \\ questionnaire consisting of seven vision- \\ specific items as well as 36-item short-form \\ survey of the Medical Outcomes Study (SF-36) \\ was administered. Stereoscopic level was \\ divided into three groups: no stereopsis, gross \\ stereopsis, and fine stereopsis. Fisher's exact \\ test was used to detect any difference in \\ subjective visual functioning and \\ Mann-Whitney $U$ test was used for analyses \\ of SF-36 scores. \\ Results A total of 187 volunteers were \\ recruited and 150 were analysed for \\ stereoscopic levels. There was no significant \\ difference in vision-specific difficulty among \\ the three stereoscopic groups. For SF-36, \\ having no stereopsis scored significantly less \\ than having gross $(P=0.005)$ and fine \\ $(P<0.0001)$ stereopsis in the vitality/energy \\ dimension. General health perception \\ dimension fared significantly lower in the \\ group with no stereopsis compared to the fine \\ stereoscopic group $(P=\mathbf{0 . 0 1})$. In multivariate \\ analysis, having fine stereopsis scored \\ significantly higher in the energy/vitality \\ dimension than having no stereopsis \\ $(P=0.02)$. On the other hand, visual \\ impairment imposed significant adverse effect \\ on five vision-specific items and had no \\ significant relationship with the eight \\ dimensions of SF-36. \\ Conclusions Defective stereopsis in the \\ elderly imposes no significant adverse effect \\ on vision-related quality of life. However, \\ subjects may feel more exhausted in \\ accomplishing their usual tasks. \\ Eye (2005) 19, 540-545. doi:10.1038/sj.eye.6701538 \\ Published online 20 August 2004
}

Department of

Taipei Veterans General

Hospital

Taipei, Taiwan

${ }^{2}$ Department of

Ophthalmology

National Yang-Ming

University

Taipei, Taiwan

${ }^{3}$ Community Medicine Research Center and Institute of Public Health National Yang-Ming University

Taipei, Taiwan

Correspondence: P Chou Institute of Public Health National Yang-Ming University

Shih-Pai, Taipei 112 Taiwan

Tel: +886228229695

Fax: +886228201461

E-mail: pschou@

ym.edu.tw

Received: 2 November 2003 Accepted: 1 March 2004 Published online: 20 August 2004

The authors have no proprietary interest in any aspect of the study.
T-M Kuang ${ }^{1,2,3}$, W-M Hsu' ${ }^{1,2}$, C-K Chou ${ }^{1,2}$, S-Y Tsai ${ }^{3}$ and $\mathrm{P} \mathrm{Chou}^{3}$

Keywords: elderly; quality of life; Short-Form 36; stereopsis; vision-related quality of life; visual impairment

\section{Introduction}

Standard visual acuity has been shown to underestimate the degree of visual function loss suffered by the elderly. ${ }^{1}$ Many older individuals have reduced stereopsis and colour discrimination. ${ }^{1}$ Stereoacuity was shown to reduce from about 16 seconds of arc ( $\mathrm{sec}$ arc) for younger age groups to about $27 \mathrm{sec}$ arc for subjects 60-70-years old. ${ }^{2}$ Jani $^{3}$ noted an increase in stereoacuity from ages 9-20 years and then a considerable reduction of stereoacuity over the age of 40 years in a volunteer study of stereopsis using the Diastereo test. While visual impairment was shown to reduce the quality of life ${ }^{4-9}$ and can cause clinical depression ${ }^{10,11}$ in the elderly, little was known about whether reduced stereopsis would induce any vision-related functional impairment and affect the well-being and general health status of the elderly. In this study, we aim to explore the relationship between defective stereopsis and quality of life in the elderly.

\section{Materials and methods \\ Selection of subjects}

The study was conducted from 1 March, 2002 to 31 September, 2002 and comprised of subjects 65 years or older who had their households registered in Guando district of Taipei city. The household registration system in Taiwan is designed and administered by the government to collect and supply demographic information and to recognize officially personal status and relations. This system also provides information for effective city planning and developmental programmes. A quota of 200 volunteers was 
recruited for a comprehensive physical examination provided by Guando Municipal

Hospital, managed and directed by Taipei Veterans General Hospital.

This study was approved by the Institutional Review Board of the Taipei Veterans General Hospital.

\section{Assessment instruments and definitions}

The general physical examination was a comprehensive standardized examination including blood pressure, weight and height measurement, general blood chemistry, urine examination, bone density screening, and ophthalmic examination that included best-corrected distance and near-visual acuity, stereoacuity, tonometry, slit-lamp biomicroscopy, and indirect ophthalmoscopy. All ophthalmic examination was performed by one senior ophthalmologist. A structured questionnaire collecting information about visionrelated quality of life and general health status was administered.

Visual acuity was assessed using a Snellen chart at a distance of $6 \mathrm{~m}$ and recorded separately for each eye, and was defined as the lowest line in which the directionality of the majority of E letters was identified correctly. Visual acuity was measured initially with the subject's glasses (if worn). If visual acuity was less than $6 / 6$, the examination was repeated with subjective refraction. If the refraction measurement could not be appropriately obtained, a pinhole-corrected acuity test was performed. Bestcorrected distance visual acuity was defined as the best of all measurements. Visual impairment was in accordance to the criteria set by the World Health Organization and International Classification of Diseases, ${ }^{12}$ a best-corrected visual acuity in the better eye of less than 20/400 for blindness and less than 20/60 but no less than 20/400 for visual impairment. Since the number of subjects with bestcorrected visual acuity worse than $20 / 400$ was too few for analysis, all subjects with best-corrected visual acuity of less than 20/60 in the better eye were considered to have impaired vision in this study.

Near-visual acuity was measured with Jaeger near-chart with subjects' near glasses, if worn. If the participant forgot to bring his/her near glasses, he/she was asked about his/her habitual near correction, and corrective lenses were provided accordingly, otherwise best Jaeger near-visual acuity achieved with naked eyes was recorded as this reflected most accurately the level of near-visual acuity in the subject's daily life.

Random dot stereo butterfly (2000 sec arc) and stereo circle patterns (nine plates with four circles in each plate; one of the four circles in each plate 'appeared forward' compared to the other three and correspond to stereoscopic levels of 800, 400, 200, 140, 100, 80, 60, 50, and $40 \mathrm{sec}$ arc respectively) (Random Dot Stereo Tests; Stereo Optical Co., Inc., Chicago, IL, USA) were then used to measure stereoscopic vision. The test was administered under standard background illumination and was measured at about $40 \mathrm{~cm}$ held by the participants. The level of stereopsis was recorded as the highest level of stereopsis correctly identified. If the participant made one mistake and had the next level of stereopsis correct, the missed one was tried again to ensure the subject really achieved that level of stereopsis instead of just guessing the more difficult one. In this study, stereoscopic level achieved was graded into three groups: no stereopsis (Randot butterfly could not be identified, $>2000 \mathrm{sec}$ arc); gross stereopsis (Randot butterfly identified correctly but none of the 'protruding' stereo circles could be correctly pointed out, $800<$ stereothreshold $\leq 2000 \mathrm{sec}$ arc) and fine stereopsis (at least one of the nine stereo circle plates correctly identified, $\leq 800 \mathrm{sec}$ arc).

A structured questionnaire consisting of seven vision-specific questions (reading small print, reading newspaper, pressing telephone numbers, performing handicraft/sewing, writing a check/letter/filling a form, playing game like mahjong/cards, cooking) was conducted by specially trained interviewers. Subjects were asked whether they performed the seven visionspecific activities in their daily lives. If they did, they were subsequently asked whether they experienced any difficulty (yes/no) with the activity. All participants were informed that they had to answer these questions in relation to their visual function alone. The 36-item short-form survey of the Medical Outcomes Study (SF-36) was also administered by the same interviewer. The SF- 36 is a general outcome measure consisted of eight distinct dimensions: (1) physical functioning, (2) role limitations due to physical problems, (3) bodily pain, (4) general perception of health, (5) vitality/energy, (6) role limitation due to emotional problems, (7) social functioning, (8) mental health and have been widely used in health policy evaluation, general population surveys and clinical research and practice. The history of development and the origin of specific items have been reported. ${ }^{13}$ Prior experience has shown the Chinese (Taiwanese) version of the SF-36 to be reliable and valid for cross-cultural application to assess self-reported functioning and well-being and have been applied in many fields of medicine. ${ }^{14-17}$ Scoring was performed using the Rand 36-Item Health Survey (version 1.0) method. Dimensional scores represent the average for all items in the particular dimension and range from 0 to 100 with a higher score being indicative of a better health status. 


\section{Statistical analysis}

Fisher's exact test was performed to detect any difference in vision-specific difficulty experienced between the three stereoscopic groups. In this analysis, subjects with distance visual acuity of less than 20/60 in either eye or binocular near-visual acuity worse than J7 were excluded for stereoscopic analysis. In other words, patients with normal visual acuity in both eyes but of different stereoscopic levels were compared for vision-specific difficulty. A $P$-value of less than 0.05 was defined as the level of significance. The same statistical strategy was also used to detect differences between subjects with normal and impaired vision.

We also evaluated the relationship between general functional status and stereoscopic acuity. Since the SF-36 scores of our participants were not normally distributed, Mann-Whitney U tests were employed to detect differences between the three stereoscopic groups. The same analysis was performed for subjects with impaired and normal vision. A $P$ value of less than 0.01 was considered to be statistically significant here in order to reduce the likelihood of making type I error due to multiple comparisons.

Multiple regressions were then performed for each of the SF-36 dimensional scores. Included as independent variables were sex, age, comorbid systemic diseases previously diagnosed by a physician: diabetes mellitus (yes/no), hypertension (yes/no), cardiovascular disease (yes/no), arthritis (yes/no), history of stroke (yes/no), history of psychiatric disease (yes/no), visual acuity (normal/impaired), and stereoacuity (no/gross/fine) with the scores of each of the eight dimensions of SF-36 as dependent variable. Statistical analysis was performed using the Statistical Analysis System (SAS 6.12; SAS Institute, Cary, NC, USA) software.

\section{Results}

A total of 187 participants took part in the general physical examination. Excluding those with poor visual acuity in either eye ( 23 participants), those who were unable to comprehend the test or declined questionnaire (14 participants), the number of subjects undertook the stereoscopic test was 150 . The average age of stereoscopic participants was $73.7 \pm 6.2$ years old (range 65.4-95.8 years) with 81 male and 69 female subjects.

The distribution of stereoacuity of our participants was shown in Table 1 . There was no significant difference between the three stereoscopic groups in terms of age and sex. Overall, $18.7 \%$ of participants had no stereopsis and $50.0 \%$ possessed fine stereopsis.

There was no difference in difficulty experienced by subjects with no stereopsis, gross stereopsis and fine
Table 1 Stereoscopic level of participants

\begin{tabular}{lc}
\hline & Number of participants (\%) \\
\hline No stereopsis & $28(18.7)$ \\
Gross stereopsis & $47(31.3)$ \\
Fine stereopsis & $75(50.0)$ \\
Total & $150(100.0)$ \\
\hline
\end{tabular}

stereopsis in performing all of the seven vision-specific tasks (Table 2). However, impaired vision was associated with significantly greater limitations in visual functioning than subjects with normal vision in five of the seven vision-specific items (except pressing telephone numbers and cooking).

Table 3 provided the means of the eight dimensions of SF-36 for the three stereoscopic groups. Having no stereopsis fared significantly lower scores in the energy/ vitality dimension than having gross $(P=0.005)$ and fine stereopsis $(P<0.0001)$. Similarly, self-perceived general health status fared significantly lower in the group with no stereopsis compared with the fine stereoscopic group $(P=0.01)$. There was no significant difference in all eight dimensions between subjects with gross and fine stereopsis. On the other hand, visual impairment had no significant impact in all eight dimensions.

In the final multiple regression analyses controlling for all covariates, having fine stereopsis scored statistically higher $(P=0.02)$ in the vitality/energy dimension compared with no stereopsis (reference group) but not in the other seven dimensions. Visual impairment was not statistically significant in the eight dimensions after multivariate analyses.

\section{Discussion}

Assessment of functioning and well-being of patients has become increasingly important in clinical investigation and evaluation of treatment outcomes in recent years. In ophthalmology, self-reported questionnaires of visual quality and general functional status have been used widely and especially in the fields of cataract, ${ }^{18,19}$ glaucoma, ${ }^{20,21}$ macular disease, ${ }^{22}$ myopia ${ }^{23}$ visual impairment, ${ }^{4,5,24}$ and blurred vision. ${ }^{25}$

Stereoacuity is considered to be an ability limited by age; ${ }^{1,2}$ however, the impact of this finding on visual functioning and general well-being in the elderly has not been fully explored.

Brabyn and Haegerstrom-Portnoy ${ }^{1}$ noted that in 900 individuals between the ages of 58 and 102 years old, many have greatly reduced stereopsis. Only $60 \%$ of 70 -year-olds and $20 \%$ of 90 -year-olds meet the $85 \mathrm{sec}$ arc criteria and $60 \%$ of 90 -year-olds cannot detect a disparity of $340 \mathrm{sec}$ arc using the Frisby stereotest. Besides, all 
Table 2 Visual quality of life at different stereoscopic and visual acuity levels

\begin{tabular}{|c|c|c|c|c|c|c|c|}
\hline & \multicolumn{4}{|c|}{ Stereopsis group } & \multicolumn{3}{|c|}{ Vision } \\
\hline & Applicable No. & No (No.) & Gross (No.) & Fine (No.) & Applicable No. & Normal (No.) & Impaired (No.) \\
\hline \multicolumn{8}{|c|}{ Reading small print } \\
\hline No difficulty & 131 & 13 & 19 & 40 & $147^{*}$ & 80 & 0 \\
\hline With difficulty & & 11 & 21 & 27 & & 61 & 6 \\
\hline \multicolumn{8}{|l|}{ Reading newspaper } \\
\hline No difficulty & 130 & 16 & 22 & 43 & $145^{*}$ & 89 & 0 \\
\hline With difficulty & & 7 & 18 & 24 & & 50 & 6 \\
\hline \multicolumn{8}{|l|}{ Telephone numbers } \\
\hline No difficulty & 139 & 21 & 37 & 66 & 156 & 135 & 4 \\
\hline With difficulty & & 4 & 5 & 6 & & 15 & 2 \\
\hline \multicolumn{8}{|l|}{ Handicraft/sewing } \\
\hline No difficulty & 99 & 9 & 18 & 35 & $111^{*}$ & 68 & 0 \\
\hline With difficulty & & 7 & 12 & 18 & & 39 & 4 \\
\hline \multicolumn{8}{|l|}{ Writing a check } \\
\hline No difficulty & 87 & 5 & 15 & 30 & $100^{*}$ & 57 & 0 \\
\hline With difficulty & & 8 & 12 & 17 & & 39 & 4 \\
\hline \multicolumn{8}{|l|}{ Playing game } \\
\hline No difficulty & 77 & 15 & 20 & 39 & $88^{*}$ & 84 & 0 \\
\hline With difficulty & & 0 & 2 & 1 & & 3 & 1 \\
\hline \multicolumn{8}{|l|}{ Cooking } \\
\hline No difficulty & 140 & 23 & 46 & 71 & 160 & 154 & 6 \\
\hline With difficulty & & 0 & 0 & 0 & & 0 & 0 \\
\hline
\end{tabular}

No. $=$ number.

${ }^{*} P<0.05$.

Table 3 Mean scores of the eight dimensions of SF-36 at different stereoscopic and visual acuity level

\begin{tabular}{|c|c|c|c|c|c|}
\hline \multirow[t]{2}{*}{ Scale } & \multicolumn{3}{|c|}{ Stereoacuity } & \multirow{2}{*}{$\begin{array}{c}\text { Impaired vision } \\
(\mathrm{n}=7) \\
\text { Mean }(S D)\end{array}$} & \multirow{2}{*}{$\begin{array}{l}\text { Normal vision } \\
\quad(\mathrm{n}=166) \\
\text { Mean (SD) }\end{array}$} \\
\hline & $\begin{array}{c}\text { No. } \\
(\mathrm{n}=28) \\
\text { Mean }(S D)\end{array}$ & $\begin{array}{c}\text { Gross } \\
(\mathrm{n}=47) \\
\text { Mean }(S D)\end{array}$ & $\begin{array}{c}\text { Fine } \\
(\mathrm{n}=75) \\
\text { Mean }(S D)\end{array}$ & & \\
\hline Physical functioning & $87.7(16.0)$ & $87.0(19.5)$ & $89.4(18.0)$ & 87.7 (18.9) & $92.9(7.0)$ \\
\hline Role limits/physical & $89.3(31.5)$ & $94.1(22.8)$ & $89.7(29.7)$ & $82.1(37.4)$ & $90.7(27.8)$ \\
\hline Bodily pain & $94.1(12.6)$ & $90.6(14.0)$ & $91.1(14.9)$ & $91.7(14.2)$ & $90.9(8.6)$ \\
\hline General health & $65.9(13.2)^{*}$ & $69.7(18.5)$ & $72.7(17.1)^{*}$ & $70.3(16.9)$ & 70.9 (24.9) \\
\hline Social functioning & 99.8 (11.6) & 97.1 (9.8). & $96.5(11.7)$ & $97.0(10.4)$ & $98.8(12.7)$ \\
\hline Energy/vitality & $72.5(11.7)^{\dagger}$ & $79.5(16.3)^{\dagger \dagger}$ & $82.1(11.3)^{\dagger \dagger}$ & $79.4(13.5)$ & $86.4(8.0)$ \\
\hline Role limits/emotional & $90.5(28.5)$ & $97.9(14.6)$ & $92.9(22.8)$ & $94.4(20.9)$ & $98.6(7.0)$ \\
\hline Mental health & $72.6(12.0)$ & $76.3(11.6)$ & $78.3(11.1)$ & $76.3(11.5)$ & $81.7(5.1)$ \\
\hline
\end{tabular}

$\mathrm{SD}=$ standard deviation; ${ }^{*}$ Indicated that group 1 was statistically different from group $3{ }^{\dagger}{ }^{\dagger}$ and ${ }^{\dagger \dagger}$ indicated that group 1 was statistically different from group 2 and group 3, while group 2 and group 3 was not significantly different from each other.

spatial vision functions show a similar rate of decline with age of the population. Similar to our findings, many people with normal visual acuity in each eye showed poor stereopsis. They suggested that stereopsis decreases with age even with maintained foveal function in each eye.

The Salisbury Eye Evaluation Study ${ }^{26}$ that recruited residents between the ages of 65 and 84 years showed that stereoacuity remained constant into the mid-70 s and declined at an accelerating rate thereafter. Randot Circles test was used in the SEE study and 14.3\% (359/2509) was stereoblind (unable to see depth at the largest stereoscopic disparity tested, $450 \mathrm{sec}$ arc). The prevalence of stereoblindness was found to increase significantly with age from $10 \%$ in the $65-69$ age group to $26.3 \%$ in the 80-85 age group.

Brown et $a l^{2}$ used a portable two rod alignment system for quantitative stereoscopic measurement. It was a freespace test of stereoacuity and subjects were required to make judgements of the position of the movable rod. They found that stereoacuity was about $27 \mathrm{sec}$ arc for subjects 60-70-years old as compared to about $16 \mathrm{sec}$ arc for the three younger age groups.

With different methods of measurement and criteria used, very different levels of stereoacuity were 
found. Despite the discrepancy, all studies concord with the findings that stereoscopic ability declined in the elderly.

Wright and Wormald ${ }^{27}$ showed that only $27 \%$ of those aged 65 years or above had full stereopsis and $29 \%$ had no stereopsis using the Frisby stereotest.

Taking 65-69-year-old group as reference, the odds ratio for loss of stereopsis for the 70-75-year-olds is 2.57 and is 7.54 for those above 80-years-old. In their survey, they found that defective stereopsis did not give rise to any subjective symptoms. However, no specific questions were asked with regard to the possible effects of reduced stereopsis.

Our visual questionnaire has power ranged from 65 to 93\% (except playing game and cooking) and the results showed that loss of stereopsis in the elderly does not impose much adverse effect on visual functioning. Reduced stereopsis did not hamper one's vision-specific functioning as compared to impaired vision. However, defective stereopsis did have a significant effect on the vitality dimension of SF-36, implying that stereopsis may affect one's general health status and well-being in a certain aspect. Owing to its limited impact on central vision, subjects without stereopsis may still perform their usual vision-specific task but may require more effort to accomplish this and hence feel fatigued and exhausted more easily. While some elderly people may have adapted stereoscopic reduction as a way of life, others may have compensated this ageing process through past experience, monocular clues, size, shading, or perspective and this requires further study. Owing to the nonprospective design of the study, it was also plausible that decreased vitality and reduced general health status led to degraded stereoacuity through decreased binocular functioning or neural processing. On the other hand, both decreased vitality and reduced stereopsis may be related to a third unidentified factor.

There has been literature suggesting that second-eye cataract surgery led to greater improvement in subjective visual functioning and quality of life than those who underwent cataract extraction in only one eye. ${ }^{28-32}$ It was suggested that disturbed motion perception and disturbed stereoacuity may be restored by cataract extraction in the second eye. ${ }^{33-35}$ Laidlaw and Harrad ${ }^{33}$ demonstrated that stereoacuity was improved in all of the 29 patients following second-eye cataract extraction and was associated with corresponding improvements in symptoms like glare, depth perception, and blurred vision. Talbot and Perkins ${ }^{34}$ showed that stereoacuity was observed in 32\% following first eye surgery and 90\% after second eye surgery (36\% had 240 sec arc or better). The number of our participants that had received secondeye cataract surgery or unilaterally pseudophakic was small to make a formal statistical comparison, but our results suggested that although stereoacuity may be an objective indicator of visual improvement, it did not seem to play an important role in subjective visual functioning and general outcome measures from the viewpoint of patients. This suggestion is in accordance with the Proyecto Vision and Eye Research Project, ${ }^{36}$ which observed that the impact of cataract on quality of life was largely mediated through its effect on acuity alone, whereas glaucoma and diabetic retinopathy have other effects on quality of life besides visual acuity. It should be noted, however, that their analysis was limited to central acuity impairment with no measurement of stereoacuity. We suggested that if the quality of life would improve after bilateral cataract surgery, this should be related to better visual acuity, widened binocular field of vision, improved motion perception or other factors. Our study further provided data-based evidence of what Wright and Wormald ${ }^{27}$ had suggested.

Visual impairment, on the other hand, has a much greater negative impact on vision-specific quality of life but did not show a significant adverse effect in general outcome measures, although it should be noted that few subjects had visual impairment among our participants.

Our study had some limitations; participants were selfselected and cognitively intact. Furthermore, whether defective stereopsis was acquired through ageing could not be ensured although the percentage of subjects without stereopsis would not be as high in a normal young age population. Williams $\mathrm{et}_{\mathrm{al}} \mathrm{l}^{37}$ reported the prevalence of defective stereopsis was between 2.1 and $3.2 \%$ in a large study of children aged between 7 and 11 years tested with a TNO random dot stereo test. A further 10-16\% had only moderate levels of stereoacuity. This is in stark contrast to our $18.7 \%$ without stereopsis in our elderly participants with normal visual acuity in both eyes. More longitudinal studies are required to determine the rate of decrease of stereopsis through ageing, the mechanism of decreased stereoacuity in the elderly and how subjects respond and adapt to this phenomenon.

Although stereoscopic decline may not induce a large adverse impact on visual functioning, but in order to improve the general quality of life in the elderly, loss of stereopsis should not be overlooked and deserves further evaluation.

\section{Acknowledgements}

This study was supported by a grant from Taipei Veterans General Hospital, Taipei, Taiwan (VGH 89-404-1, VGH 90-445-1, and VGH 91-382-1). 


\section{References}

1 Haegerstrom-Portnoy G, Schneck ME, Brabyn JA. Seeing into old age: vision function beyond acuity. Optom Vis Sci 1999; 76(3): 141-158.

2 Brown B, Yap MK, Fan WC. Decrease in stereoacuity in the seventh decade of life. Ophthalmic Physiol Opt 1993; 13: 138-142.

3 Jani SN. The age factor in stereopsis screening. Am J Optom 1966; 43: 653-657.

4 Branch LG, Horwowitz A, Carr C. The implications for everyday life of incident self-reported visual decline among people over age 65 living in the community. Gerontologist 1989; 29: 359-365.

5 Rubin GS, Roche KB, Prasada-Rao P, Fried LP. Visual impairment and disability in older adults. Optom Vis Sci 1994; 41: 750-760.

6 Carabellese C, Appollonio I, Rozzini R, Bianchetti A, Frisoni GB, Frattola L et al. Sensory impairment and quality of life in a community elderly population. J Am Geriatr Soc 193; 41 401-407.

7 Stelmack J. Quality of life of low-vision patients and outcomes of low-vision rehabilitation. Optom Vis Sci 2001; 78: 335-342.

8 Wang JJ, Mitchell P, Smith W, Cumming RG, Attebo K. Impact of visual impairment on use of community support services by elderly persons. The Blue Mountains Eye Study. Invest Ophthalmol Vis Sci 1999; 40: 12-19.

9 Rovner BW, Shmuely-Dulitzki Y. Screening for depression in low-vision elderly. Int J Geriatr Psychiatry 1997; 12: 955-959.

10 Rovner BW, Ganguli M. Depression and disability associated with impaired vision: The MoVIES Project. J Am Geriatr Soc 1996; 44: 181-184.

11 Tsai SY, Cheng CY, Hsu WM, Su TPT, Liu JH, Chou P. Association between visual impairment and depression in the elderly. J Formos Med Assoc 2003; 102: 86-90.

12 World Health Organization. Manual of the International Statistical Classification of Diseases, Injuries, and Causes of Death, Vol 1. World Health Organization: Geneva, 1977.

13 Ware JE Jr, Sherbourne CD. The MOS 36-item short-form health survey (SF-36): I. Conceptual framework and item selection. Med Care 1992; 30: 473-483.

14 Chie WC, Huang CS, Chen JH, Chang KJ. Measurement of the quality of life during different clinical phases of breast cancer. J Formos Med Assoc 1999; 98: 254-260.

15 Fuh JL, Wang SJ, Lu SR, Juang KD, Lee SJ. Psychometric evaluation of a Chinese (Taiwanese) version of the SF-36 health survey amongst middle-aged women from a rural community. Qual Life Res 2000; 9: 675-683.

16 Wang SJ, Fuh JL, Lu SR, Juang KD. Quality of life differs among headache diagnoses: analysis of SF-36 survey in 901 headache patients. Pain 2001; 89: 285-292.

17 Fuh JL, Wang SJ, Lee SJ, Lu SR, Juang KD. Quality of life and menopausal transition for middle-aged women on Kinmen island. Qual Life Res. 2003; 12: 53-61.

18 Steinberg EP, Tielsch JM, Schein OD, Javitt JC, Sharkey P, Cassard SD et al. The VF-14. An index of functional impairment in patients with cataract. Arch Ophthamol 1994; 112: 630-638.

19 Friedman DS, Tielsch JM, Vitale S, Bass EB, Schein OD, Steinberg EP. VF-14 item specific responses in patients undergoing first eye cataract surgery: can the length of the VF-14 be reduced? Br J Ophthalmol 2002; 86: 885-891.

20 Wilson MR, Coleman AL, Yu F, Bing EG, Sasaki IF, Berlin K et al. Functional status and well-being in patients with glaucoma as measured by the medical outcomes study Short Form-36 questionnaire. Ophthalmology 1998; 105: 2112-2116.

21 Nelson P, Aspinall P, Papasouliotis O, Worton B, O'Brien C. Quality of life in glaucoma and its relationship with visual function. J Glaucoma 2003; 12: 139-150.

22 Hazel CA, Petre KL, Armstrong RA, Benson MT, Frost NA. Visual function and subjective quality of life compared in subjects with acquired macular disease. Invest Ophthalmol Vis Sci 2000; 41: 1309-1315.

23 Rose K, Harper R, Tromans C, Waterman C, Goldberg D, Haggerty C et al. Quality of life in myopia. Br J Ophthalmol 2000; 84: 1031-1034.

24 Scott IU, Schein OD, West S, Bandeen-Roche K, Enger C, Folstein MF. Functional status and quality of life measurement among ophthalmic patients. Arch Ophthalmol 1994; 112: 329-335.

25 Lee PP, Spritzer K, Hays RD. The impact of blurred vision on functioning and well-being. Ophthalmology 1997; 104: 390-396.

26 Rubin GS, West SK, Muñoz B, Bandeen-Roche K, Zeger S, Schein $\mathrm{O}$ et al. A comprehensive assessment of visual impairment in a population of older American: The SEE Study. Invest Ophthalmol Vis Sci 1997; 38: 557-568.

27 Wright LA, Wormald RPL. Stereopsis and ageing. Eye 1992; 6: 473-476.

28 Javitt JC, Steinberg EP, Sharkey P, Schein OD, Tielsch JM, West MD et al. Cataract surgery in one eye or both: a billion dollar per year issue. Ophthalmology 1995; 102: 1583-1593.

29 Lundström M, Stenevi U, Thorburn W. Quality of life after first- and second-eye cataract surgery: five-year data collected by the Swedish National Cataract Register. J Cataract Refract Surg 2001; 27: 1553-1559.

30 Javitt JC, Brenner MH, Curbow B, Legro MW, Street DA. Outcomes of cataract surgery: improvement in visual acuity and subjective visual function after surgery in the first, second, and both eyes. Arch Ophthalmol 1993; 111: 686-691.

31 Laidlaw DAH, Harrad RA, Hopper CD, Whitaker A, Donovan JL, Brookes ST et al. Randomised trial of effectiveness of second eye cataract surgery. Lancet 1998; 352: 925-929.

32 Elliott DB, Patla AE, Furniss M, Adkin A. Improvements in clinical and functional vision and quality of life after second eye cataract surgery. Optom Vis Sci 2000; 77: 13-24.

33 Laidlaw A, Harrad R. Can second eye cataract extraction be justified? Eye 1993; 7: 680-686.

34 Talbot EM, Perkins A. The benefit of second eye cataract surgery. Eye 1998; 12: 983-989.

35 Kwapiszeski BR, Gallagher CC, Holmes JM. Improved stereoacuity: an indication for unilateral cataract surgery. J Cataract Refract Surg 1996; 22: 441-445.

36 Broman AT, Munoz B, Rodriguez J, Sanchez R, Quigley HA, Klein $\mathrm{R}$ et al. The impact of visual impairment and eye disease on vision-related quality of life in a MexicanAmerican population: Proyecto VER. Invest Ophthalmol Vis Sci 2002; 43: 3393-3398.

37 Williams S, Simpson A, Silva PA. Stereoacuity levels and vision problems in children from 7 to 11 years. Ophthalmic Physiol Opt 1988; 8: 386-389. 